\title{
From Shells to Tensile Structures: A Personal History
}

\author{
Matthys Levy ${ }^{1}$ (iD
}

\begin{abstract}
World renowned engineer Matthys Levy shares his experiences with shells and tensile structures over the course of a career that has spanned seven decades and included works that ranged from small-scale embassy buildings and showrooms to large hotels, to extremely large stadiums and hi-rise buildings.
\end{abstract}

Keywords Shell structures · Tensile structures · Wide span structures

\section{Shell Structures}

In the fall of 1954, I arrived at Columbia University to take a graduate degree following two years of army service in a construction battalion in Korea. Having been away from the classroom for more than three years, I needed to improve my mathematical skills and enrolled in a course on numerical methods in engineering. The professor who introduced himself on the first day of class was Mario Salvadori, a Roman refugee who spoke English with a precise, clipped accent and who presented the most complicated mathematical concepts with absolute clarity. Here was an immigrant like myself, whom I decided to emulate...if possible. First, I asked him to be my thesis advisor and then, naturally, I signed up for another course he taught, on the analysis of shell structures. I had previously been seduced on seeing published images of the shell structures designed by the Mexican Architect, Felix Candela and the Italian Engineer, Pier Luigi Nervi so it was natural for me to undertake such a course. It turned out that Salvadori knew these designers and I was able to meet them both during the period of my graduate studies, when they were invited to lecture at Columbia.

Matthys Levy

matthyslevy@gmail.com

140 College St., Burlington, VT 05401, USA 
After obtaining my degree, I was introduced by Mario to Paul Weidlinger, a Hungarian émigré who had established a consulting engineering office and who needed an engineer familiar with shell design. Although at that time, my knowledge was purely academic, I was immediately thrust into the practical aspects of shell design by working on the St. Louis Priory Church designed by Gyo Obata, a structure that consisted of cylindrical shells supported by concrete arches (Fig. 1).

I first struggled with the shapes, trying to find those that most nearly approached the funicular of the loads. I found that parabolic arches most closely approximated the catenary... a lesson that I learned by studying Gaudí's Sagrada Famiglia. The aim as always, was to make the shell as thin as possible to avoid bending stresses but at the same time thick enough to protect the reinforcing. This was solved through a compromise of the competing requirements with a thickness of $50 \mathrm{~mm}$. My singular contribution to that project was proposing a concept for the forming system. I suggested that forms be built for only five of the twenty sectors. Then, three could be moved sequentially around the circular plan. This experience made me keenly aware that formwork in shell construction constituted a major part of the cost and needed to be minimized through reuse whenever possible.

In the following years, I participated in the design and execution of numerous shell structures. For the US Embassy in Baghdad, we designed hyperbolic paraboloid shells over the ambassador's residence, folded plate shells over the office building and cylindrical shells over the staff quarters (Fig. 2).

For the architect/woodworker, George Nakashima, we designed a conoidal shell for his showroom (Fig. 3). Two wooden shells, one in the form of a hyperbolic paraboloid and the other, a conoid were also designed for Nakashima to illustrate how plywood could be formed into shells (Fig. 4).

For Mount Clemens Federal Savings and Loan Association in Mt. Clemens, Michigan, we developed a unique, translational surface shell to which four conically curved legs were wedded (Fig. 5).

On the shore of the Caribbean in San Juan, Puerto Rico, a nightclub called La Concha was roofed in a concrete seashell surrounded by a reflecting pool (Fig. 6).

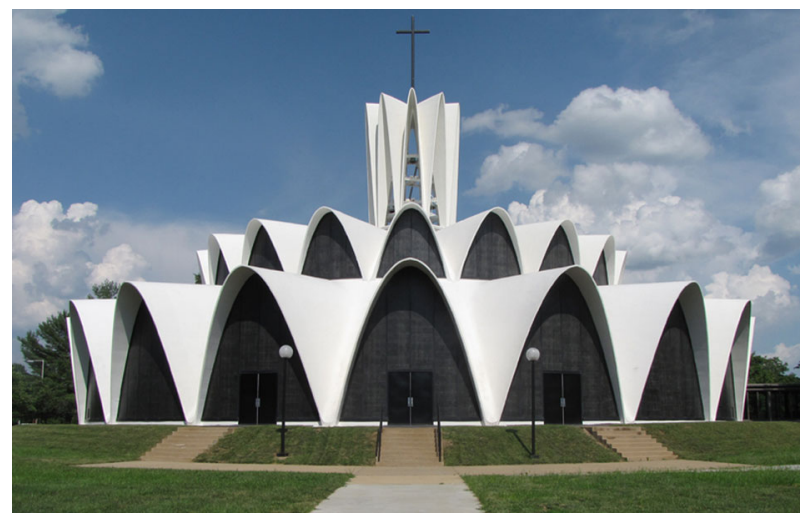

Fig. 1 St. Louis Priory (now St. Louis Abbey), architect: Gyo Obata for HOK, engineers: Weidlinger Associates, Creve Coeur, Missouri, USA, completed 1962 

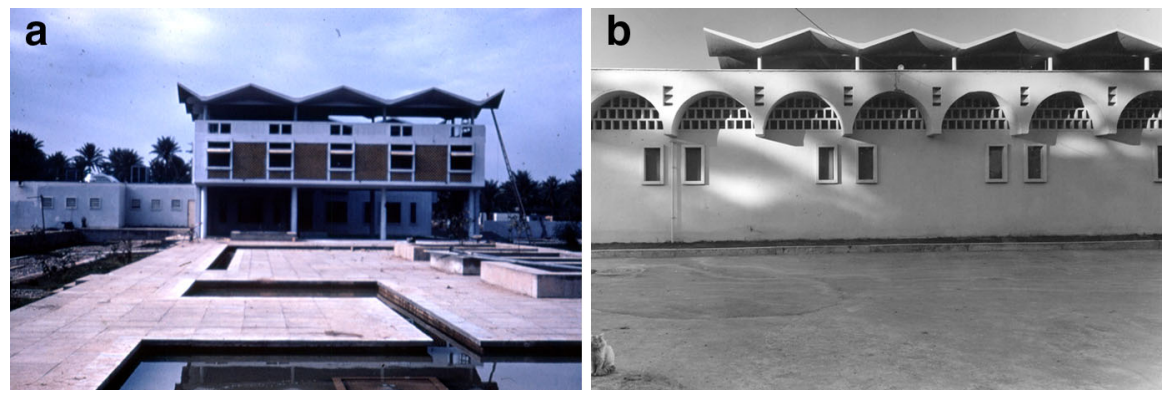

Fig. 2 U.S. Embassy, architect: Josep Lluís Sert for Sert/Jackson, engineers: Weidlinger Associates, Baghdad, Iraq, completed 1961: a front elevation, during construction; b side elevation

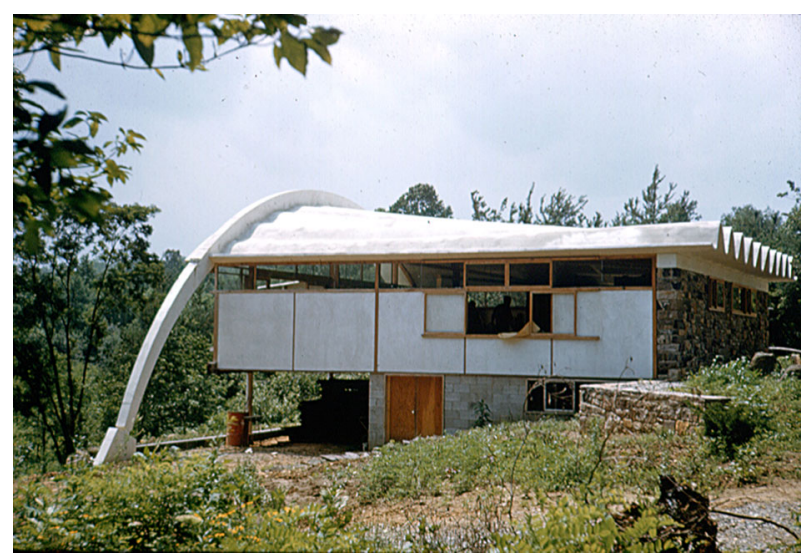

Fig. 3 George Nakashima Woodworker, Conoid Studio, engineers: Weidlinger Associates, 1847 Aquetong Road, New Hope, Bucks County, PA, shown under construction, completed 1957

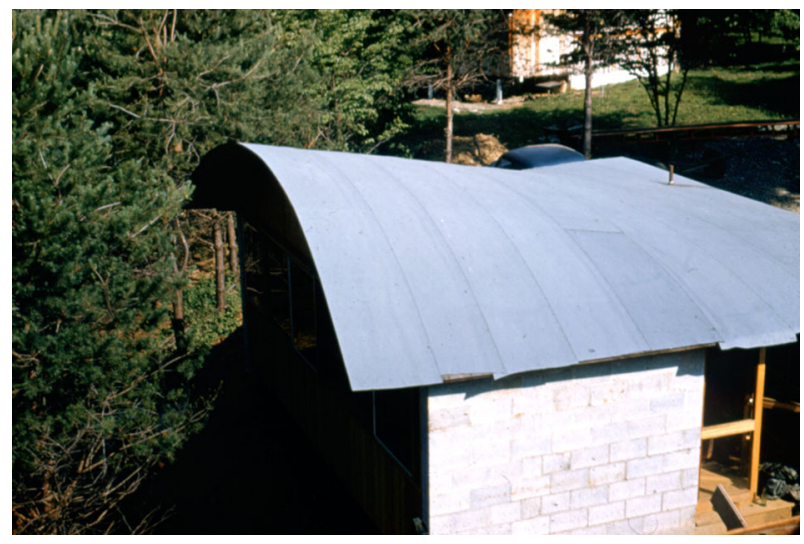

Fig. 4 Wooden shell designed for George Nakashima 


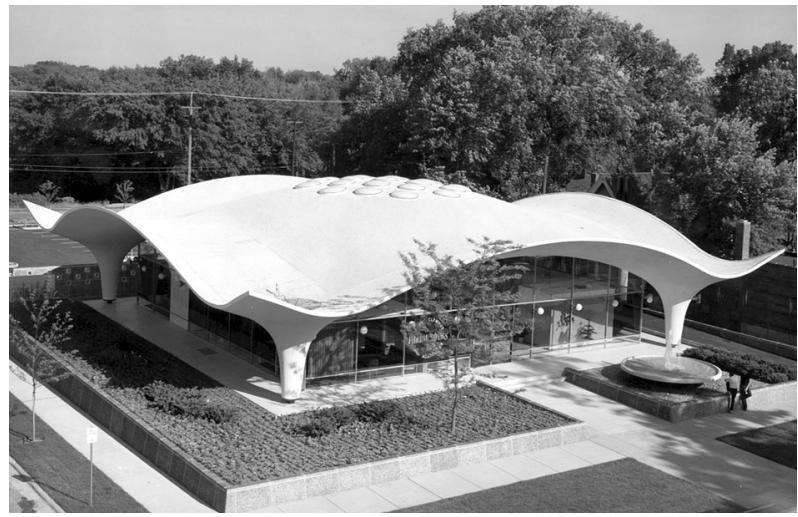

Fig. 5 Mount Clemens Federal Savings and Loan Association, architect: William Kessler for Meathe Kessler, Architects, engineers: Weidlinger Associates, Mt. Clemens, Michigan, completed 1961 (today restructured as "The Vault" nightclub)
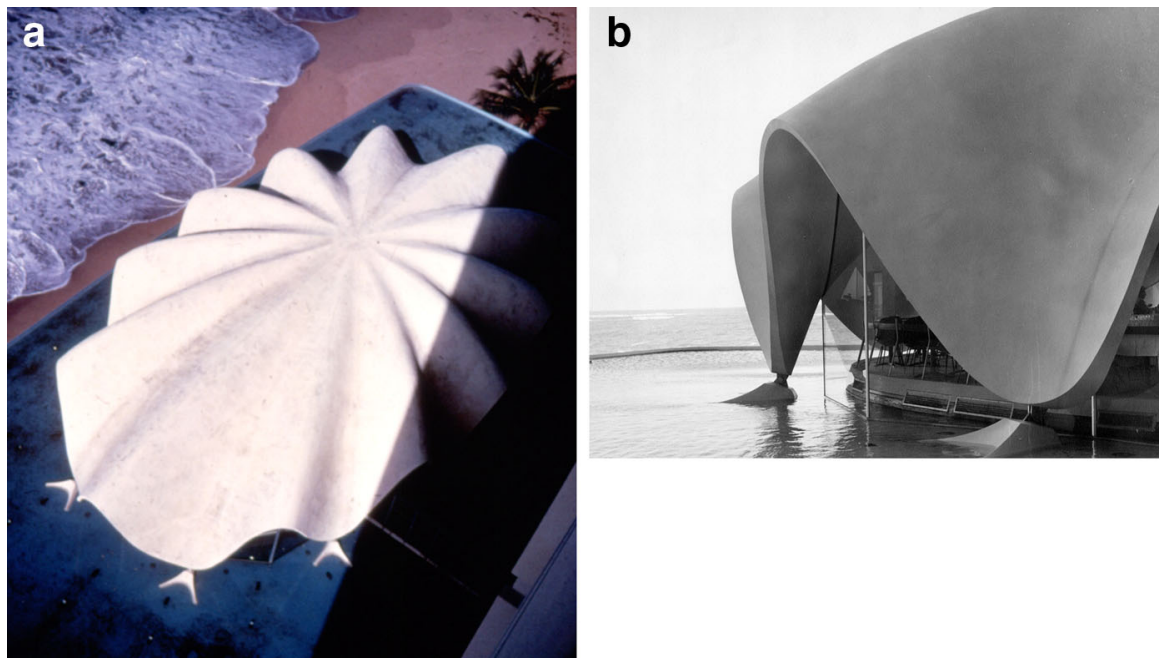

Fig. 6 La Concha Beach Resort (Renaissance Hotel, now Perla restaurant), architects: Warner, Burns Toan \& Lundy and Torro y Ferrer, engineers: Weidlinger Associates, San Juan, Puerto Rico, completed 1958: a bird's eye view; b ground level view

This continuously variable thickness shell was $60 \mathrm{~mm}$ thick at the top and $200 \mathrm{~mm}$ thick at its stainless steel support hinges.

For the University of Baghdad, the mosque designed by Walter Gropius, was designed in the form of a peaked dome in the shape of a Saracen helmet carved out to provide only three points of contact with the ground. This presented a unique challenge for the design analysis before the age of computers (Fig. 7). For the purpose of analysis, the shape was simplified by modeling an upper dome-shaped element supported by three inward-sloping triangular legs. The design lay dormant for almost a decade during which computer modeling was developed. Before 


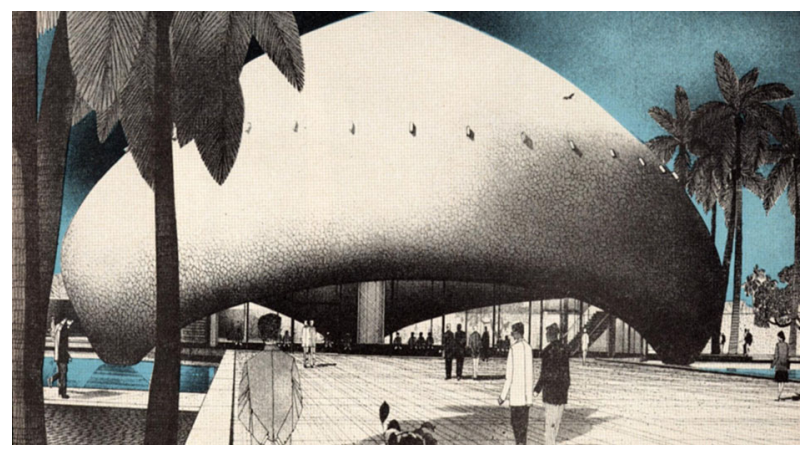

Fig. 7 University of Baghdad Mosque, architects: Walter Gropius and Hisham A. Munir, engineers: Weidlinger Associates, Baghdad, Iraq, designed 1957

construction was authorized, a redesign was undertaken using the new technology that led to a significant $30 \%$ saving in required reinforcing.

The 25-year period from the early 1950s was the golden age of shell construction around the world. However, as the cost of concrete shell construction increased due to the need for expensive formwork, fewer shells were built especially those that needed non repetitive formwork.

\section{A Space Frame Interlude}

At the turn of the twentieth century, Alexander Graham Bell recognized that extending the inherent rigidity of a triangular array of bars into three dimensions forming tetrahedra, resulted in a space frame, a strong and stable structure. Space frame structures to span over large areas such as convention facilities and airport terminals became popular in the second half of the twentieth century. A number of different commercial space frame systems were developed-Mero, Octet, and Cubic, among others - each using a unique joining element at the nodes; Mero, for instance uses a ball node into which bolt-end tubular pipes are screwed. I first designed a space frame for the roof of a convention facility in Birmingham, Alabama completed in the early 1970s that used conventional welded and bolted bars rather than a patented node. That project was designed using approximations for the member forces derived from a two-way slab analogy, a conservative approach in the absence of computer modeling that became available later.

The opportunity to develop the most unique application of space frame technology came in the late 1970s with the design of the Jacob Javits Convention Center in New York. The architect for this project was James Freed of Pei Cobb Freed. The design called for a space frame roof of $60,000 \mathrm{~m}^{2}$, not just for a flat roof over the exhibit space but with vertical bays popping up to new higher roof sections (Fig. 8).

The challenge was to devise a structural system that would unify the building's stepped roofline and supporting structure. The plan of the center is made up of 

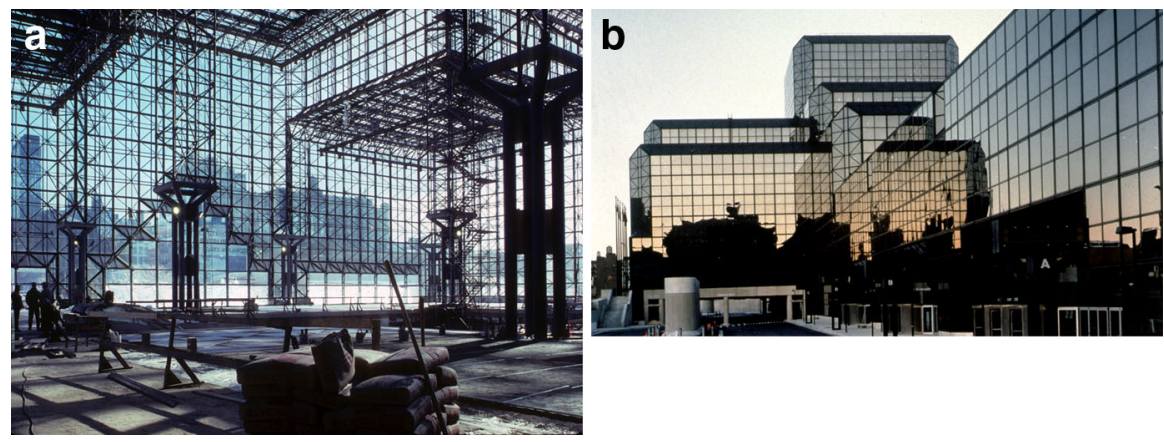

Fig. 8 Jacob Javits Convention Center, architect: James Freed for Pei Cobb Freed, engineers: Weidlinger Associates, New York City, New York, completed 1986: a during construction; b shown completed

repetitive $3 \mathrm{~m}$ square modules, $1.5 \mathrm{~m}$ deep, supported $27 \mathrm{~m}$ on center in both directions. The space frame was further stiffened by adding a diamond truss using the same tetrahedral geometry along each column line. The whole behaves in a manner analogous to a flat plate with reinforced column strips. At the columns, a third layer of space frame was added to create a drop panel, completing the analogy. Away from the exhibit area, the roofline steps upward to delineate an entrance hall and a galleria with a geometry that is integral with the space frame concept and utilizes the same tetrahedral elements to turn both horizontal and vertical corners. The structural rhythm therefore flows seamlessly from horizontal to vertical planes. Even the columns supporting this space frame are fitted with an inverted pyramidal capital providing four points $3 \mathrm{~m}$ apart to support the dropped portion of the roof at each column location. These were affectionately termed "martini columns". This project benefited from the availability of computer programs for both analysis and member design.

\section{Tensile Structures}

\section{Metropolitan Boston Arts Center (MeBAC)}

Progressing to tensile structures, in 1958, a temporary summer theatre in Boston, Massachusetts. was planned using a large canvas circus tent. However, the architect, Carl Koch, wanted to avoid the center post typically found in such a tent. An alternate structure for the roof was proposed by Paul Weidlinger that used an inflated fabric membrane in the shape of a lens, attached around its perimeter to a column supported steel ring. The membrane was proposed as a vinyl coated nylon fabric that was kept rigid with compressed air pumped into the space between both surfaces. Prior applications of air supported structures for tennis bubbles and storage warehouses typically sprung from the ground and trapped the patrons or goods inside the air structure. Instead, having the air-inflated roof floating above the patrons provided $1600 \mathrm{~m}^{2}$ of unencumbered area where people could move about freely (Fig. 9). 


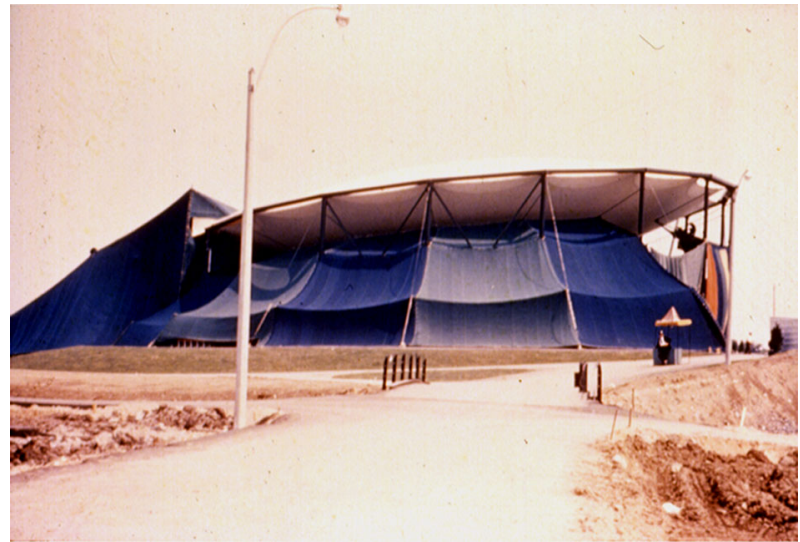

Fig. 9 Metropolitan Boston Arts Center (MeBAC) summer theater, architect Carl Koch, engineers: Weidlinger Associates, Boston, Massachusetts, 1958

The circular roof with a diameter of $43.5 \mathrm{~m}$ was $6 \mathrm{~m}$ deep at the center, equivalent to a $76 \mathrm{~m}$ radius of curvature for each of the two membranes. Since the roof was to be used only in the summers, the only load considered for the design was wind. Because of its relatively flat profile, the wind forces were actually minimal, with local uplift near the leading edges partially offset by the spoiler effect of the steel ring. This resulted in a design load of $0.5 \mathrm{kN} / \mathrm{m}^{2}$ for the upper membrane and the same internal pressure acting on the lower membrane. The nylon fabric used in this application had previously been used by the fabricator, Walter Bird for radomes ${ }^{1}$ but this was the first time that he had been faced with a sealed, pill-shaped roof. To reinforce the edges, Bird suggested the use of a plastic-coated aircraft cable draped as a catenary between points of attachment to the perimeter steel ring. The two membranes that were separately manufactured were joined together in the field along the edge with an oversized zipper. The resulting roof, apart from the steel ring weighed only $1.5 \mathrm{~kg} / \mathrm{m}^{2}$, remarkably small for a roof of this size. The original concept for this structure included using the fabric pill as a form for pouring a thin shell concrete roof and fireproofing the steel with concrete, thus converting the temporary structure to a permanent one. This was never done and, in fact, the roof was scheduled to be dismantled at the end of its first successful use as a summer theatre. Unfortunately, a hurricane descended on Boston before workers were able to lower the roof and it was torn apart by the force of the devastating winds-a sad end to a unique fabric structure.

\section{Carlton Center}

A number of years later, the opportunity arose for a second application of the pill concept, this time for a slightly smaller roof over a skating rink in Johannesburg,

\footnotetext{
${ }^{1}$ Walter Bird developed the pneumatic structures known as "radomes" in the 1940s for the United States Air Force as portable structures to protect radar antennas from environmental factors such as wind and rain that could interrupt the signal.
} 


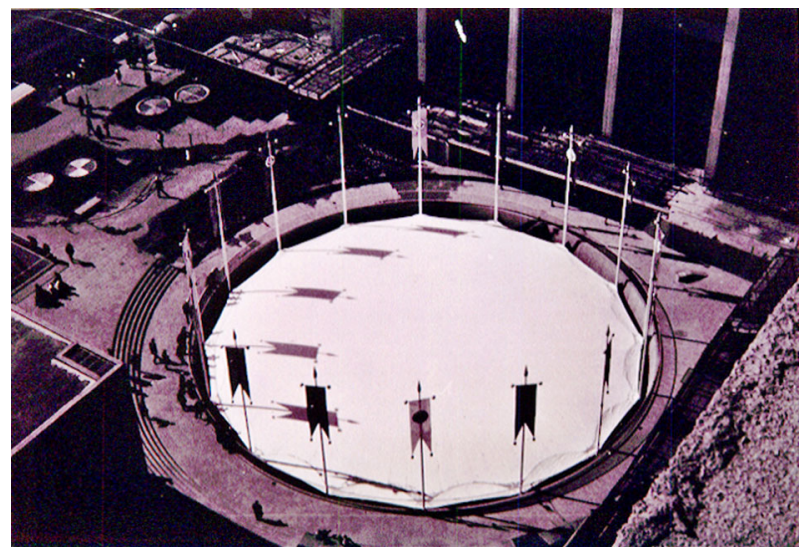

Fig. 10 Carlton Centre skating rink, architect Gordon Bunshaft for SOM, engineers: Weidlinger Associates, Johannesburg, South Africa, completed 1972

South Africa (Fig. 10). By that time, the industry had matured and a higher quality fabric was available, Teflon coated fiberglass. Because of the high tensile strength of this new fabric it was possible to reduce the bulbous appearance of the pill to a sleek profile.

\section{University of Riyadh}

In the early 1970s we were engaged to design a college arena in the desert. For this structure, we proposed an idea first used by David Geiger for the 1970 World's Fair in Osaka, Japan. The arena we designed consisted of a low profile, cable-stiffened air-supported roof (Fig. 11).

\section{Georgia Dome}

The opportunity for a major advance in lightweight tensile structure design came in 1987 with the commission for a 70,000 seat football stadium in Atlanta, Georgia. Oval in plan, the roof of this stadium spans $193 \times 240 \mathrm{~m}$. Building on an idea first expounded by Buckminster Fuller in 1954 that he called an "aspension dome", we developed a novel design that we called "Tenstar Domes". Fuller proposed a design that featured a series of ever smaller steel plate hoops spaced in from an outer compression ring to the center of the arena. These hoops were to be supported first by cables from a perimeter compression ring to the bottom of the first interior hoop followed by cables from the top of that hoop to the bottom of the next interior hoop and so on until reaching the center of the dome. We modified the concept, replacing the steel hoops with steel posts, an idea first proposed by David Geiger for a circular arena in Seoul, and then introducing diagonal cables supporting these posts instead of the radial cables used by Geiger. Switching to a triangular arrangement of cables permitted us to achieve any plan configuration achieving a high degree of stiffness of the resulting structure (Fig. 12). It also proved ideal for conforming to the oval 


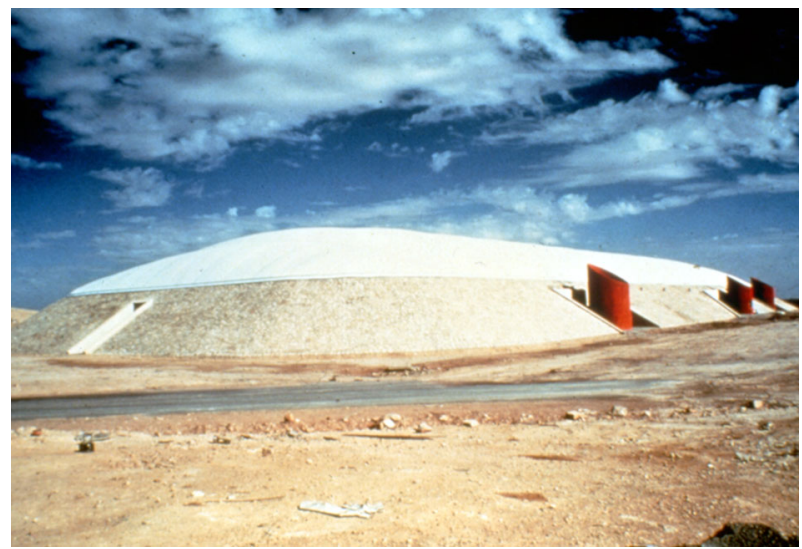

Fig. 11 University of Riyadh arena, engineers: Weidlinger Associates, Riyadh, Saudi Arabia, completed 1978

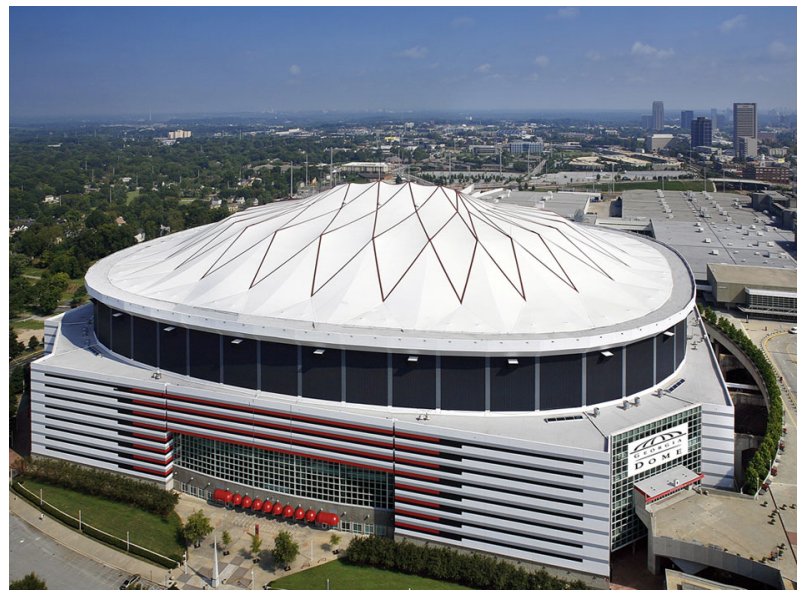

Fig. 12 Georgia Dome, architects: FABRAP \& Heery International, engineers: Weidlinger Associates, Atlanta, Georgia, USA, completed 1992

configuration of the football stadium. The structure can be thought of as consisting of trusses where the bottom chord is interrupted and detours along the lines of the hoops to the other side. The top chord cables laid out in a triangular geometry result in saddle shaped panels that were fitted in this case, with a Teflon coated fiberglass fabric. The spacing of the roof segments was established based on the largest practical fabric panel width, limited by the permissible stress in the fabric that turned out to be under $30 \mathrm{~m}$.

Finally, joining the various parts of the structure proved to present a challenge. Since this is not a rigid structure, it was necessary to maintain flexibility between the posts and the top cable net as well as between the posts and the bottom hoop cables. For practical reasons such as the limitation on the size of spools for transporting 
cables, the maximum cable diameter was chosen as $100 \mathrm{~mm}$. This resulted in bottom hoops with as many as four cables. The node connecting the hoop cables to the vertical post and diagonal cables were designed as weldments rather than castings for reason of economy. Even though the plan of the roof oval had been regularized using only two circular segments (one for the sides and one for the ends), there were still too many different node types needed to make casting cost effective. The nodes at the top of the posts were also complicated since the cables on either side of a node lie in two different planes. A bent plate with steel bars welded to it to create saddles for the continuous top chord cables solved that problem.

The cable roof structure is connected to a perimeter compression ring that apart from restraining the dome, mediates between the geometry of the cable dome and the geometry of the stands below; whereas the cable dome uses two circular segments, the stands use three to approximate an oval. The compression ring is an $8 \times 2.4 \mathrm{~m}$ concrete box beam centered on guided Teflon pads at the top of concrete columns.

The dead load of the completed cable dome is an incredible low $0.3 \mathrm{kN} / \mathrm{m}^{2}$ and supports, in addition to normal wind and snow loads, an array of catwalks to permit servicing lights, speakers and rigging for special events. This structure was completed in 1991.

\section{La Plata "Twindome" Stadium}

In 1997 Roberto Ferreira won a competition for a new sports complex in La Plata, Argentina, that included a 45,000 seat soccer stadium. The proposal for the stadium was unique insofar as it sought to provide an identity to the two football teams scheduled to play there. This was achieved with a plan that was derived from two intersecting $170 \mathrm{~m}$ diameter circles $48 \mathrm{~m}$ apart, creating what looks like a MasterCard symbol. We proposed a roof for the stadium using the Tenstar Dome concept we had developed for the Georgia Dome. However, because of the reentrant corners on the two sides where the two circles intersect, this design turned out to be much more complicated. An arch-like structure divides the two halves of the roof requiring rigid members for the top chord and some bottom chord members. This arch structure introduced a new variation to the previous cable dome design and demonstrated the adaptability of the Tenstar Dome concept to unusual geometries (Fig. 13).

At the perimeter of the roof is a triangular steel compression ring about $9 \mathrm{~m}$ wide and about $13 \mathrm{~m}$ high (conforming to the changing elevations of the top of the bermed seating bowl. The vertical posts of this compression truss form a colonnaded gallery at the back of the stand. Skyboxes and control booths are suspended within the compression ring from a series of trapeze hangers.

The arena is naturally ventilated with an open perimeter and $15 \mathrm{~m}$ diameter openings at each of the two peaks of the roof. These are covered with a sky-lit crown and perimeter rain screen giving the impression of a sombrero, but this is still in the future as the structure was built in stages. It started with the construction of the bowl for the stands and the compression ring structure that were both completed 


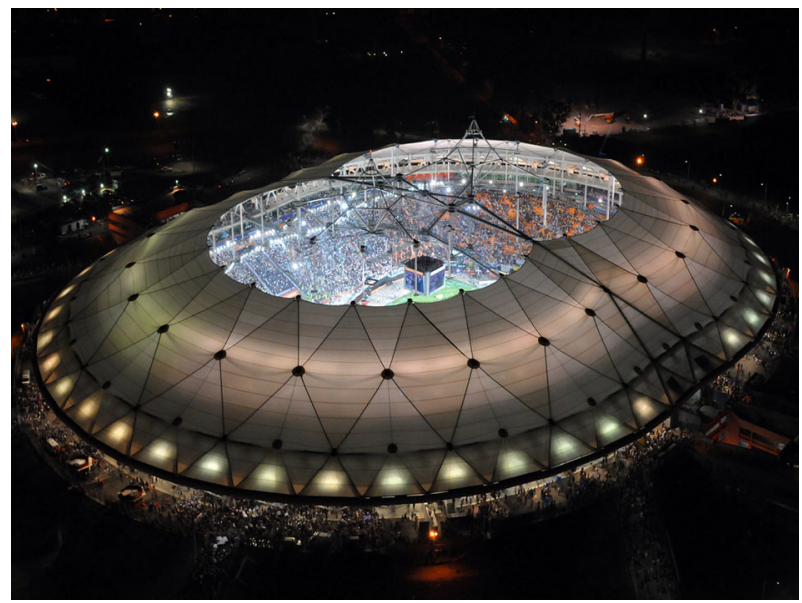

Fig. 13 La Plata Stadium, Architect: Roberto Ferreira, engineers: Weidlinger Associates, La Plata, Argentina. 2013

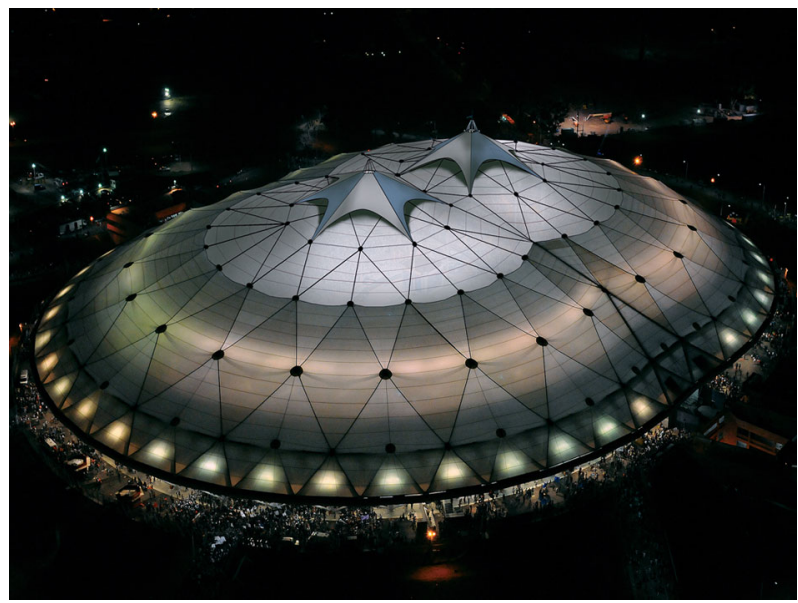

Fig. 14 La Plata Stadium, final roof configuration

in 2000. Financial problems delayed the start of the next stage until 2013 and included the erection of the cable dome using a $24 \%$ translucency Teflon coated fiberglass fabric to form an annular ring over the stands. A final stage to complete the fabric covering over the center of the roof awaits another tranche of financing (Fig. 14). 


\section{The Future}

As can be seen from the examples above, innovation in design comes about both as a result of need and in response to the latest available analytical tools and material technology. When the designers of the velarium proposed a solar shade over the stands of the Roman Coliseum, they did so out of a need to protect the spectators from the intense heat of the sun. But, they realized that the shade did not need to remain in place permanently so the designers chose to make it retractable. That was 2000 years ago and the velarium was only a sunshade and not a protection against rain! Today, retractable roofs over arenas and stadiums are needed because rain and snow are impediments to the use of a facility in inclement weather. Yet in good weather, spectators to sporting events want to be outdoors. To meet that need, retractable roofs have been built using steel trusses riding on rails and that are covered with either rigid or fabric roofs.

For a bullfight arena in Saragoza, Spain, Jörg Schlaich was faced with an existing structure that could not take the weight of a heavy trussed roof. So, he came up with a different idea using a circular cable roof with fabric supported along radial cables with a 36 m diameter curtain-like section that can be gathered toward an area above the middle of the arena.

For large stadiums, the Tenstar Dome concept suggests another approach.

We developed a retractable roof concept compatible with the flexible structure of a cable dome, initially in 1993 for a project in Busan, Korea (Fig. 15). That structure, which was circular in plan, was designed with four pie-shaped operable section that would open to reveal a circular oculus. Each of these sections was to consist of linked, flexible carriages covered with steel arch stiffened fabric, creating a continuous series of saddle-shaped sections (Fig. 16).

Since the retractable carriages are lighter than the possible wind uplift forces, the bogey wheels ride in channel-shaped track sections to provide support for both gravity and uplift forces. The articulation of the carriages is such that they can flex in two directions, conforming to the flexibility of the supporting cable dome. The

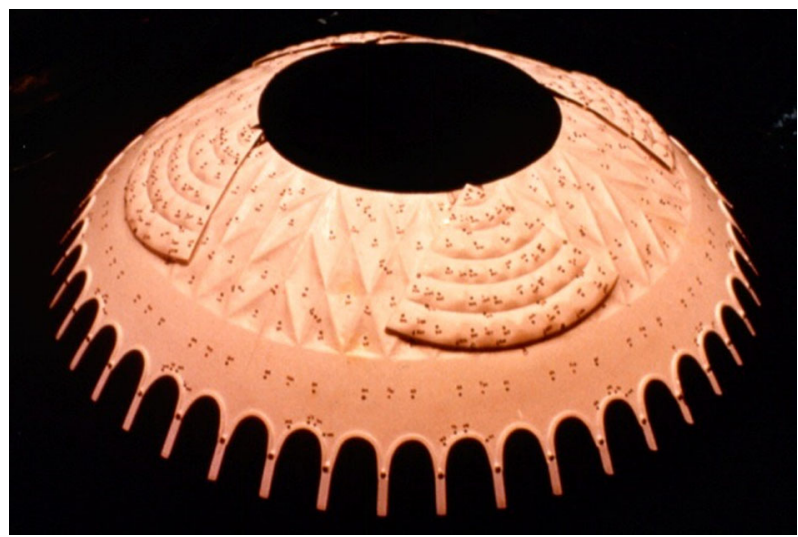

Fig. 15 Design for a retractable cable dome in Busan, South Korea, 1993 


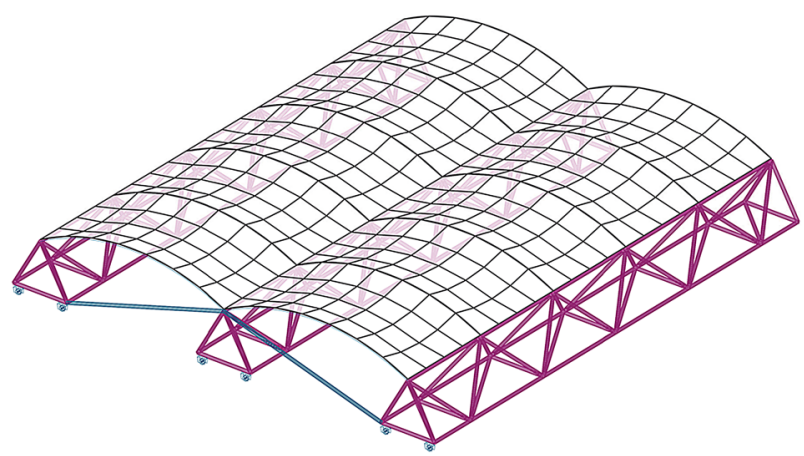

Fig. 16 Saddle-shaped moveable carriages for the Busan cable dome

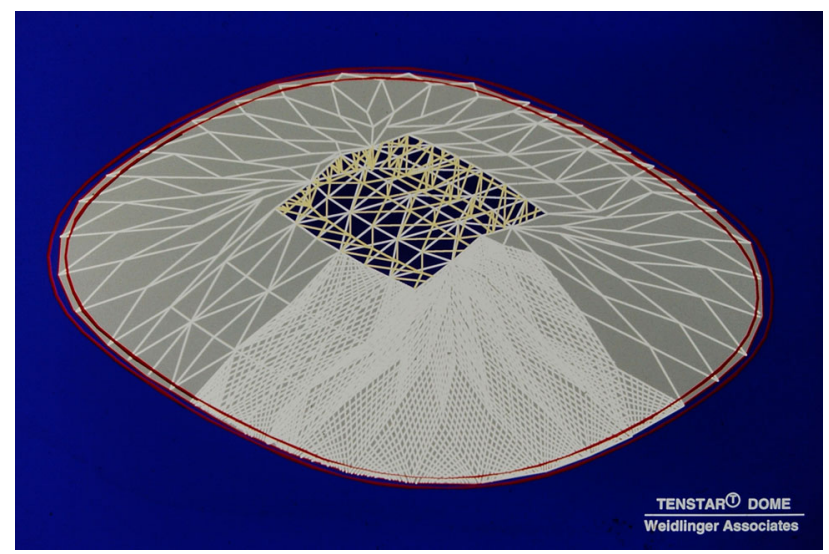

Fig. 17 Design for a Retractable Tenstar Dome

concept for the traction system was a chain drive in which the drive sprockets are mounted on the movable roof and a continuous chain rests on a channel in the sectional rails. The chain loops around idler sprockets and engages the drive sprocket. Electric motors are mounted on the movable roof above each wheel and are sized to permit opening or closing of the roof within $15 \mathrm{~min}$. Each leaf of the movable roof is fitted with multiple drivers, electronically interconnected to eliminate yawing of the leaf. The roof is expected to operate under winds of less than $10 \mathrm{~m} / \mathrm{sec}$ and automatic controls will stop the movement should winds exceed this velocity.

This concept can be applied to a rectangular opening over a football stadium or tennis arena. All that is needed is a substructure of a cable dome with parallel cables on the top chord (Fig. 17).

For the carriages, an alternate concept is possible, involving the use of folding panels, somewhat like a roman shade, necessitating the use of a fabric that will flex without breaking, such as polyester instead of fiberglass. Both of these are feasible proposals that only await a future client. 


\section{Conclusion}

I have witnessed a period of spectacular advances in materials and technology in the almost seventy years since I first put pencil to paper and slid my slide rule back and forth to design the still magnificent roof of the St. Louis Priory. These advances have guided my designs and led to an increase in efficiency and complexity. Subsequent generations went from guiding a pencil across a sheet of paper to tapping a keyboard while staring at a computer screen, from pushing a slide rule to keying in commands in a mechanical calculator and now a digital computer. Older materials such as steel and concrete have improved and are dramatically stronger. New materials have come into use such as high-strength fabrics, transparent films and ceramics. All these improvements have been incorporated into original structures. But, the real story for the future is that for every improvement in materials and in analytical technology, there are designers who will find how to use these in novel and innovative ways. In the coming years, I expect to see spectacular designs created by architects and engineers open to these advances.

Acknowledgements All photographs are courtesy of the author.

Matthys Levy is a founding Principal and Chairman Emeritus of Weidlinger Associates, now merged with Thornton Tomasetti. A graduate of the City College of New York, Mr. Levy received his MS and CE degrees from Columbia University. He has been an adjunct professor at Columbia University and a Distinguished Professor at Pratt Institute and a lecturer at universities throughout the world. Mr. Levy is the recipient of many awards, including an AIA Institute Award, and has published numerous papers in the field of structures, computer analysis, aesthetics and building systems design: He is the author of six books including Why Buildings Fall Down, with Mario Salvadori. He is the inventor of the patented Tenstar Dome structure, a unique tensegrity cable dome used to span over large spaces. He has appeared on numerous television shows including NOVA, Modern Marvels, the History Channel, ABC News, PBS series on Domes and others. Mr. Levy has served as an expert in forensic investigations including the World Trade Center Collapses in New York, the Versailles Ballroom Collapse in Jerusalem, and the failure of the UNI Dome in Iowa. 